\title{
Application of a Multi-Annual Generalized Depletion model to the Mediterranean sandeel fishery in Catalonia
}

F. Maynou*, M. Demestre, P. Martín, P. Sánchez

Institut de Ciències del Mar, CSIC, Psg. Marítim de la Barceloneta 37-49, 08003Barcelona (Spain)

\begin{abstract}
A multi-annual generalized depletion (MAGD) model was applied to the data-limited Mediterranean sandeel boat seine fishery in Catalonia. The results show that catch and effort data at high temporal frequency (month), complemented with biological information on mean body weight and initial estimates of natural mortality and time of recruitment to the fishery, can be used to produce assessment results of interest to fisheries management. The estimates of fishing mortality obtained for the Mediterranean sandeel in this fishery are very low compared to natural mortality estimates (less than 10\%) and the important fluctuations in recruitment strength suggest that the dynamics of this fishery are mainly driven by density-dependent effects on the population dynamics of the species. Given the high rate of natural mortality estimated $\left(\sim M=2 \mathrm{yr}^{-1}\right)$, its short life-span (1-2 years) and that exploitation is based on age 0 individuals, it is recommended to keep exploitation rates at current levels $(<4 \%)$, which can be adapted on a short time basis, subject to the perceived availability of the stock. This low exploitation rate is compatible with a precautionary escapement biomass of $40 \%$. A parallel stock assessment was carried out with a surplus production model (SPiCT), which led to similar trends in biomass and fishing mortality as the MAGD model application. The parameter estimates obtained with both models have wide confidence intervals, particularly for the quantities related to population size, suggesting that these data-limited models are likely to suffer from low precision. Precision was lower for SPiCT than for MAGD, and the performance diagnostics for SPiCT were poor. The MAGD model can be used for small-scale fisheries that are unlikely to meet the requirements of standard stock assessments based on catch-at-age methods and can provide indicators (fishing mortality, vulnerable biomass) of interest to fisheries managers.
\end{abstract}

Keywords: data-limited fisheries; depletion models; Mediterranean sandeel; stock assessment; boat-seine fisheries

*contact person:

maynouf@icm.csic.es

running title: data-limited assessment of Mediterranean sandeel fishery

Journal: FISHERIES RESEARCH 


\section{Introduction}

The assessment of Mediterranean fish stocks is often hampered by lack of complete data sets fulfilling the requirements of standard stock assessment based on catch-at-age models (Lleonart and Maynou, 2003; Caddy, 2009). Standard stock assessments require long time-series of commercial fish catches, demographic structure of the population and other biological data, and usually, an independent index of fish abundance (Haddon, 2011). In recent years, the situation for Mediterranean fisheries has improved for target species of the main fishing fleets, thanks to stock assessments carried out under the umbrella of the STECF (Scientific, Technical and Economic Committee for Fisheries) or GFCM (General Fisheries Commission for the Mediterranean) (Colloca et al., 2013). Data of sufficient quality are inevitably available for important fish stocks subject to regular monitoring programmes. However, several dozens of species are routinely commercially harvested in Mediterranean fisheries for which standard stock assessment is impractical or too expensive. In data-limited situations (sensu Johannes, 1998; Prince, 2003) fisheries assessment methods alternative to the standard Virtual Population Analysis family must be considered, making best use of whatever type of data is available (Caddy, 2009).

In Catalonia (NW Mediterranean) a traditional small scale fishery targeting sandeels with boat seines (known as sonsera, name for the boat and the fishing gear) has since 2012 been the focus of a specific management plan (Lleonart et al., 2014), that serves as example of co-management in small scale fisheries. This fishery catches two species of sandeel, Gymnammodytes cicerelus and Gymnammodytes semisquamatus (Sabatés et al., 1990), but by far the most abundant in the catches is the former (around $90 \%$ of individuals). Sandeels are short-lived forage fishes found in shallow sandy bottoms between 5 and $15 \mathrm{~m}$ depth of the colder areas of the Mediterranean Sea and adjacent Atlantic Ocean. Individuals of both species rarely reach $15 \mathrm{~cm}$ TL and are easily distinguished by a bluish shade in the skin of G. cicerelus (known in Catalan as "sonso blau" o blue sandeel, FAO name "Mediterranean sandeel") and a brownish shade in $G$. semisquamatus ("sonso ros", blonde sand-eel, FAO name "smooth sandeel"). Unlike the industrial sandeel fishery in the North Sea that harvests hundreds of thousands of tonnes for reduction to fishmeal (Lindegren et al., 2018) the Catalan small-scale fishery yields less than one thousand tonnes annually. Small scale boats (6 to $10 \mathrm{~m}$ length overall, engine power 20-60 kW: Martín et al., 2016) operate on a daily trip basis and landings are entirely aimed at the fresh, direct human consumption market, as the species is highly appreciated in the region and fetches a good price (ca. $10 € / \mathrm{kg}$ ex-vessel price).

The co-management plan of the sonsera fishery was implemented because this fishery was deemed not legal when the European legislation (EU Reg. 1967/2006) prohibited the use of boat seines, due to their perceived negative impact on coastal ecosystems: the net employs a small mesh size, the boats operate at short distance from the coast and the net can occasionally be towed along the sea bottom, threatening vulnerable seagrass beds of the Mediterranean endemic Posidonia oceanica. Therefore, the fishery was forced to close on March 2012 and could only be reopened after establishing a management plan. On April 2012 a co-management committee was organized, composed by fishers, fisheries administration, NGOs and scientists and permanently established (Lleonart et al., 2014). The committee drafted a management plan that was eventually submitted to the STECF and approved by the European Commission. The objectives of the sonsera management plan are to maintain a sustainable fishery by means of limiting the catches of the target species, avoiding Posidonia vulnerable habitats and regulating non-target catches to very low levels discard and by-catch rates. 
The currently authorized fleet is limited to 26 vessels operating from six fishing ports along the Catalonian coast: Barcelona, Arenys de Mar, Blanes, Sant Feliu de Guíxols, Palamós and L'Estartit. No new licenses for this fishery can be issued. The number of fishers on board is either 2 or 3 . The seine has two lateral wings with a maximum length of $125 \mathrm{~m}$ followed by a cod-end of $30 \mathrm{~m}$. The maximum height of the gear wings is $30 \mathrm{~m}$ from the surface. Control follows the rules of standard monitoring and the precautionary approach (Caddy, 2009), including, among other, the daily reporting of catches to the co-management committee, the sale of catches exclusively through the official channel of auction at the home ports, and reducing the quota or even stopping the fishery during the season if catch per unit effort is perceived to decline excessively. The fishery is regulated by a monthly quota (Total Allowable Catch) that is allocated per boat and day, combined with limitation of fishing effort, that means that only some of the 26 authorized vessels can fish a certain number of days per month (Lleonart et al., 2014). A closure of the fishery is enforced during the spawning period, from 15 December to 1 March. Monitoring is not stopped during this period, and twice a month experimental fishing with scientific observers on-board professional sonsera boats permit to record biological information (abundance, sizes, maturity stage, bycatch and discards, if any). Fishers and the co-management committee may decide, based on the monitoring during the closure and/or catches in the first week of March, to open the fishing season and the quotas for the first fishing month. The fishery is fully dependent on recruitment, which takes place around March-April.

The fishery of sandeel showed important fluctuation in catches during the studied period making it very difficult to assess the level of exploitation. Stock assessment based on pseudocohorts during the period August 2012 to July 2013 showed that the stock appeared to be in healthy state and the sonsera fleet had no difficulty in catching the established monthly quotas at the end of the fishing season (Lleonart et al., 2014). Nevertheless, the successive years were markedly different and the fishery had to be closed in some years (2015 and 2016) before the end of the season by recommendation of the co-management committee, following the criteria of precautionary management.

The main objective of this study was to test the applicability of the multi-annual generalized depletion (MAGD) model to provide estimates of exploitation levels and fish abundance for fisheries with limited information, with the example of the sonso fishery as case study. The model was examined under a range of initial parameter values, informed with basic knowledge on the species, and compared to a classical surplus production model.

\section{Material and Methods}

\subsection{Data source}

The sonsera management plan includes the twice-monthly sampling of individual size (Total Length, TL) and weight (g) from the commercial catches, as well as the daily monitoring of catches by boat $(\mathrm{t})$ and fishing effort (number of vessels per month). These high frequency data collected over several years and combined with limited additional information on the biology of the species can be employed for stock assessment using recent developments on depletion models, such as the Multi-Annual Generalized Depletion (MAGD) model (Roa-Ureta, 2012, 2014). The application of the MAGD model is relatively straightforward with the CatDyn v. 1.1-1 library of the R statistical environment, but it requires good starting estimates for the model parameters, particularly natural mortality $(M)$ and the magnitude and timing of the perturbation events (corresponding to annual recruitment pulses). Information on individual fish weight (mean body weight) is also necessary to convert the landings in weight to 
numbers. The study period, with gaps due to close seasons, comprises the years 20122019. The original data set is summarized in Table 1.

Table 1. Phases in the scientific monitoring of the co-managed Mediterranean sandeel (Gymnammodytes cicerelus) fishery in Catalonia 2012-2019.

\begin{tabular}{lll}
\hline period & scientific activities & management context \\
\hline Aug 2012-Jul 2013 & pilot study & pre co-management plan \\
$2014 ;$ first half of 2015; & full monitoring except in the & under co-management plan \\
$2016-2019$ & winter 2.5-months closed & \\
& season & \\
Jun-Oct 2015 & monitoring interrupted due & under co-management plan \\
& to poor catches and fishery & \\
& closure & \\
\hline
\end{tabular}

For the application of the MAGD model, a monthly time series of catch and effort was reconstructed from 2012-2019 (8 years, 96 months) setting to 0 the catches and effort during the fisheries closure periods. The MAGD model follows the dynamics of the fish population in terms of number of individuals, so it was necessary to convert catches in weight to catches in numbers, which was achieved through the mean individual weight of the biological samples routinely obtained. To follow individual growth and population growth during the months with no biological sampling, we estimated the mean body weight of the population at each month by bootstrapping the existing mean body weight data to generate a normal distribution function with the same properties of mean, standard deviation and $95 \%$ confidence intervals, using functions in the Runuran R library (Leydold and Hörmann, 2012). Fig. 1 A-D show the evolution of catches, effort, catch per unit effort and mean body weight of G. cicerelus in the study period.

Fig. 1. Data series for the Mediterranean sandeel fishery in Catalonia for the period 2012-2019. A: Monthly landings of the Mediterranean sandeel Gymnammodytes cicerelus; B: Fishing effort measured as the effective number of operating vessels month $^{-1}$; C: Landings per unit effort; D: individual fish mean body weight.

\subsection{Multiannual general depletion model}

Generalized depletion models keep track of fishery removals to estimate vulnerable biomass. In addition to removals due to fishing, natural mortality $(M)$ also contributes to deplete the population of the stock (Chapman, 1974). For one stock and one fleet, Chapman's depletion model is:

where $C_{t}$ is catch in numbers at time $t=1 \ldots T$ ( $T=96$ in our application), $q$ is the catchability coefficient, $E_{t}$ is fishing effort at time $t$ (in number of vessels month ${ }^{-1}$ in our application), $N_{0}$ is an estimate of the initial number of fish in the population, and $M$ is the natural mortality, taken as constant for the study period. The sum over $i$ cumulates the catches over the study period, assuming $C_{0}=0$. The quantity between the outer brackets models the depletion of the initial number $\left(\mathrm{N}_{0}\right)$ as a result of natural mortality and catch.

In the multi-annual generalized depletion (MAGD) model (Roa-Ureta, 2012, 2014), annual pulses of recruitment in an age-structured population are interpreted as perturbations that reset the depletion process. For a MAGD model running at monthly 
scale, the set of perturbations $\left\{R_{\mathrm{j}}\right\}$ can happen in month $p_{j}$, where $j$ is the number of perturbations $(j=1, \ldots, 8$ in our application, corresponding to the annual recruitment of Mediterranean sandeel as if happens during a single month each year). Additionally, the MAGD model assumes that catchability $q$ is possibly non-linearly related to fish abundance $N$ :

where $k$ is a catchability factor, and $\beta$ measures the response of catch-per-unit effort to fish abundance: $\beta$ is 1 when catchability is proportional to abundance, $\beta<1$ when catchability varies less than population numbers (hyperstability) and $\beta>1$ when catchability varies more than population numbers (hyperdepletion) (Hilborn and Walters, 1992; Harley et al., 2001). Furthermore, catches may be non-linearly related to fishing effort:

where $\alpha$ is a proportionality parameter between fishing effort and catches that can account for nonlinear effects (Roa-Ureta, 2014). Finally, the complete formulation of the MAGD model for one stock and one fleet is (Roa-Ureta, 2014):

The number of model parameters is 14 in our application to the Mediterranean sandeel stock: 8 corresponding to the perturbations representing the annual recruitment peak, natural mortality $(M), N_{0}, 3$ parameters related to catchability $(\alpha, \beta$ and $k$ ) and the $\sigma$ parameter of the error distribution function (normal or lognormal). The latter is the dispersion parameter of the likelihood function (normal or lognormal, see below).

The initial values of the parameters were established from basic knowledge on the species and the fishery by means of distribution functions from which 10000 candidate parameter sets were drawn to feed the exploratory CatDynExp tool in the CatDyn package (Roa-Ureta, 2012, 2014). CatDynExp helps explore initial parameter values before proper fitting the using with the CatDynFit tool. For annual natural mortality $(M)$ a likely range of values was obtained from two models in FISAT II (FAO, 2005): Rikhter and Efanov's (1976) method based on the time of "mass spawning", and Pauly's (1978) empirical relationship between $M$, temperature and von Bertalanffy parameters. A third estimator of $M$ used was Hoenig's (2005) model, based on the longevity of the species. For $G$. cicerelus the three $M$ estimates obtained were 1.36, 1.42 and $2.16 \mathrm{yr}^{-1}$, respectively. With these results a uniform distribution was used to sample annual mortality from the $90 \%$ of the lower value to $110 \%$ of the higher value (Table 2 ).

The timing of the annual recruitment peaks was explored visually by examining the "catch spike" using the statistic proposed in Roa-Ureta (2014), which helps identify spikes in the series of catches not explained by concurrent spikes in fishing effort:

where $X_{t}$ is the observed catch in numbers. For the Mediterranean sandeel and knowing that recruitment to the fishery occurs in spring, when the catches are composed mainly of small individuals around $4 \mathrm{~cm}$ TL, the perturbations in the catch spike were established visually a priori corresponding to the month of April of each year (i.e. months 4, 16, 28, etc.; Supplementary Material 1) and allowing a variation of 1 month (i.e. March to May) in each year (Table 2).

Table 2. Initial parameter space for the application of the Multi-Annual General Depletion (MAGD) model. Each parameter was sampled 10000 times from the distributions shown. The 
lognormal distribution $\mathrm{LN}(\mathrm{mu}, \mathrm{CV})$ is the exponent of a normal distribution with parameters $\mathrm{N}\left(-1 / 2 \log \left(1+C V^{2}\right)\right.$, $\operatorname{sqrt}\left(\log \left(1+C V^{2}\right)\right)$, where $C V$ is the coefficient of variation.

\begin{tabular}{lll}
\hline model parameter & units & distribution function \\
\hline M & month $^{-1}\left(\mathrm{yr}^{-1}\right)$ & Uniform \\
& & {$[0.10-0.20] \mathrm{month}^{-1}$} \\
& & $\left([1.22-2.38] \mathrm{yr}^{-1}\right)$ \\
peak of recruitment & month & Uniform \\
(perturbations $\left.\mathrm{p}_{\mathrm{j}}\right)$ & & {$[3-5]$} \\
N0 (Jan. 1) & $\times 10^{9}$ individuals & $\operatorname{LN}(5.500,0.4)$ \\
R1 (2012) & $\times 10^{9}$ individuals & $\operatorname{LN}(3.822,0.4)$ \\
R2 (2013) & $\times 10^{9}$ individuals & $\operatorname{LN}(3.822,0.4)$ \\
R3 (2014) & $\times 10^{9}$ individuals & $\operatorname{LN}(3.822,0.4)$ \\
R4 (2015) & $\times 10^{9}$ individuals & $\operatorname{LN}(0.194,0.4)$ \\
R5 (2016) & $\times 10^{9}$ individuals & $\operatorname{LN}(0.194,0.4)$ \\
R6 (2017) & $\times 10^{9}$ individuals & $\operatorname{LN}(0.194,0.4)$ \\
R7 (2018) & $\times 10^{9}$ individuals & $\operatorname{LN}(3.822,0.4)$ \\
R8 (2019) & $\times 10^{9}$ individuals & $\operatorname{LN}(3.822,0.4)$ \\
$\alpha$ & -- & $\operatorname{LN}(1.0,0.5)$ \\
$\beta$ & -- & $\operatorname{LN}(1.0,0.5)$ \\
k & $\times 10^{-3}$ & $\operatorname{LN}(1.0,0.5)$ \\
$\sigma$ & -- & $\operatorname{LN}(1.0,0.5)$ \\
\hline
\end{tabular}

To provide initial values for the magnitude of the recruitment peaks $(R j)$ in number of individuals we used the observation that recruits weigh about $1 \mathrm{~g}$ and, consequently, there should be around $1 \times 10^{6}$ individuals in $1 \mathrm{t}$ of catches. Knowing that peak landings $\left(C_{\mathrm{j}}\right)$ in low-landings years are about $10 \mathrm{t} \mathrm{month}^{-1}$ and they are around $100 \mathrm{tmonth}^{-1}$ in high years (Fig. 1A), we can assume that the number of individuals caught in the month of the recruitment peak are of the order of $10^{7}$ and $10^{8}$, in low and high years, respectively. Solving for the Baranov-Gulland catch equation (Haddon 2011, p. 352) for a wide range of fishing mortality values (from $10 \%$ of natural mortality $\left(0.015 \mathrm{month}^{-1}\right)$ to $200 \%$ of natural mortality $\left(0.30\right.$ month $\left.\left.^{-1}\right)\right)$ :

we obtained that number of individuals at recruitment peaks $(R j)$ should be $0.24-3.64$ x $10^{8}$ for low recruitment years and $0.41-7.23 \times 10^{9}$ individuals for high recruitment years. For $N_{0}$ we assumed values in the higher end of recruitment, from $10^{9}$ to $10^{10}$. Both for $R_{\mathrm{j}}$ and $N_{0}$ lognormal distribution with a coefficient of variation of 0.4 ensured that $95 \%$ of the values sampled would be within the initial ranges proposed (Table 2 ).

For the parameters $\alpha, \beta, \mathrm{k}$ and $\sigma$, a lognormal with mean 1.0 and coefficient of variation of 0.5 ensured that the parameter space explored was sufficiently wide (from 0.3 to 2.1 approximately). In the case of $\mathrm{k}$, the catchability coefficient, the values were scaled by $10^{-3}$ (Table 2 ).

The final model parameters were estimated by maximizing the likelihood function of the difference between the observed catch series and the predicted catch series $\boldsymbol{L}(\theta$, $\left.\left\{\mathrm{X}_{\mathrm{t}}, \mathrm{C}_{\mathrm{t}}\right\}\right)$, assuming that catch in number at time step (month) is a random variable with errors modelled as normal or lognormal distribution functions: 
where $\theta$ is a vector of parameters, and $\sigma^{2}$ is the variance of the distribution, assumed to be constant in time. The starting values for $\theta$ were the median values of the converging subset $(96 \%)$ of the parameter sets obtained in the 1,000 replicates of the CatDynExp initial estimates produced from sampling the parameter space in Table 2. The model estimation was performed with the R package CatDyn v. 1.1-1 (Roa-Ureta, 2012, 2014), with the options CG (conjugate gradient optimization) and spg (spectral projected gradient), as recommended in Roa-Ureta (2014) to facilitate optimization and increase the probability of successful convergence. The number of iterations supplied to the optimizer was 10,000.

Parameter estimation with CatDynFit was performed in 4 modalities: options CG and spg for the optimization algorithm, to facilitate convergence of the optimizer (RoaUreta, 2014), and lognormal and normal error distributions, which assume that observation error is multiplicative and additive, respectively (Roa-Ureta 2012). The model fit with lowest AIC was selected among all the model runs. In addition to the model parameters the CatDyn package provides also an estimate of population number $(N)$, biomass vulnerable to the fishing gear $(B)$, exploitation rate $(\%)$ and fishing mortality $(F)$.

\subsection{Logistic production model}

To obtain an independent estimate of the sandeel abundance and for comparative purposes, the parameters of a surplus production model were estimated with the SPiCT model (Pedersen and Berg, 2017; library spict v.2.1-8 of R programming environment), leveraging on the availability of a quarterly time series of catch and effort for the period 2000-2019, provided by the Catalonia Fisheries Authority. This data series (Supplementary Material 2) is included in the regular monitoring of catches and effort carried out since 2000 for all stocks and fleets, but in the case of Mediterranean sandeel has the problem of possible misreporting of catches for the years before the inception of the management plan (2000-2011), although nominal effort is accurate. The data series and results are shown in Supplementary Material 2.

2.4 MAGD model results for fisheries advice

The Catalonia sandeel fisheries management plan has been implemented since 2012 with only generic objectives ("ensure the sustainability of the fishery") and in the absence of formal stock assessment. Management actions are based on allocating the total annual quota of $819 \mathrm{t}$ at a monthly scale among a subset of the total 26 licensed vessels (the total annual quota was derived empirically during the first year of the management plan, based on landings from the previous three years). This can be seen as management based on "empirical reference points" (Dowling et al., 2018), where a comanagement committee sets the number of authorized vessels and their maximum permitted catch based on triggers. In our case, the trigger may be a perceived decline of population abundance, deduced from observing falling catch rates. However, being a co-management scheme without formal assessment, the perception of the state stock on a short-time basis may vary among stakeholders, which implies continuous pressure on the management authority to increase or reduce the number of vessels that it is thought can harvest the quota.

Management plans for short-lived (annual) species with strong year to year variability, as is the case of the Mediterranean sandeel and many cephalopod stocks worldwide, should attempt to leave sufficient number of spawners at the end of the season to increase the probability of good recruitment for the next season (Beddington et al., 1990). This strategy can be implemented by allowing a minimum, safe number of spawners to rebuild the stock (proportional escapement through constant harvest rate). The strategy of applying a constant harvest rate can exploit information on the catch rate 
of individual vessels (and escapement observed in previous fishing seasons) to establish the amount of fishing effort per unit time (week, month) to ensure a certain level of proportional escapement by the end of the fishing season. This strategy has the advantage that the harvest rate can be calculated from the start of the season and total effort modulated on a short term basis as the season progresses. Formally, the management objective should be to define a value for the escapement rate desired at the end of the year. For instance, $40 \%$ proportional escapement is often recommended for cephalopods (Beddington et al., 1990). Proportional escapement is the number of spawners at the end of the fishing season (here, December) relative to the spawners that would have survived had there been no fishing:

where $F$ is the instantaneous fishing mortality rate and $\tau$ is the duration of the fishing season in the time units chosen. In practice, $H$ can be estimated as the season progresses (taking into account the standard deviation of the parameter estimates $q$ and $\alpha$, if required) from:

\section{Results}

\subsection{Stock assessment}

The model configuration with the lowest AIC $=1513.674$ was spg optimization with lognormal error (the CG optimization algorithm produced an AIC only slightly larger 1513.694, while assuming normal error distribution produced still larger AIC values and the model failed to converge in some cases). The observed and predicted catch by the selected model (lognormal distributed errors with spg optimization, Fig. 2 top) fit reasonably well, especially during the last five years when landings were lower. The deviance residuals were approximately normal and clustered around 0 (Fig. 2 bottom left). There was no appreciable trend in the deviance residuals (Fig. 2 bottom centre). The observed vs predicted catch (Fig. 2 bottom right) plot shows that the model has a certain bias for very high values, of 0.040 billion individuals and more. These values correspond to the recruitment peaks of the first three years in the series 2012-2014 (Fig. 2 top) that are not well captured by the model. The parameter estimates of the selected model are given in Table 3.

Fig. 2. Diagnostic plots for the application of the Multi-Annual General Depletion Model to the Mediterranean sandeel fishery. The selected configuration was a model with spg optimization and lognormal error. Top: observed and predicted catch (in 109 individuals). Target symbols along the $x$-axis represent the timing of recruitment peaks. Bottom left: Histogram of deviance residuals; Bottom middle: deviance residuals long time; Bottom right: observed vs predicted plot with 1:1 line shown.

Table 3. Final parameter estimates for the Multi-Annual General Depletion model applied to the Mediterranean sandeel (Gymnammodytes cicerelus) Catalonia fishery. The selected configuration was a model with spg optimization and lognormal error. $\mathrm{Rj}$, annual perturbation (number of recruits, with month of estimated peak recruitment).

\begin{tabular}{llr}
\hline model parameter & \multicolumn{1}{c}{ value } & \multicolumn{1}{c}{ CV (\%) } \\
\hline M & 0.219 month $^{-1}\left(2.625 \mathrm{yr}^{-1}\right)$ & $54.2 \%$ \\
NO & $58.88 \times 10^{9}$ individuals & $464.7 \%$ \\
R $_{1}(2012$ April) & $6.74 \times 10^{9}$ individuals & $511.1 \%$
\end{tabular}




\begin{tabular}{lrr}
$\mathrm{R}_{2}$ (2013 March) & $53.77 \times 10^{9}$ individuals & $453.5 \%$ \\
$\mathrm{R}_{3}$ (2014 April) & $18.14 \times 10^{9}$ individuals & $435.3 \%$ \\
$\mathrm{R}_{4}$ (2015 April) & $4.60 \times 10^{9}$ individuals & $295.5 \%$ \\
$\mathrm{R}_{5}(2016$ March) & $1.44 \times 10^{9}$ individuals & $319.5 \%$ \\
$\mathrm{R}_{6}(2017$ March) & $0.98 \times 10^{9}$ individuals & $242.4 \%$ \\
$\mathrm{R}_{7}(2018$ March) & $4.46 \times 10^{9}$ individuals & $319.4 \%$ \\
$\mathrm{R}_{8}(2019$ March) & $19.31 \times 10^{9}$ individuals & $397.3 \%$ \\
$\alpha$ & 1.74 & $14.9 \%$ \\
$\beta$ & 0.74 & $38.2 \%$ \\
$\mathrm{k}$ & $9.92 \times 10^{-5} /$ vessel & $142.8 \%$ \\
$\sigma$ & 0.67 & $20.2 \%$ \\
\hline
\end{tabular}

Supplementary Material 3 shows the results of the other three candidate models. The model with lognormally distributed errors and CG optimization provided very similar results (Fig S3.1), with the main difference being the larger size of recruitment in 2015 obtained under CG optimization than under the spg algorithm (10.46 billion individuals against 4.60 billion, cf. Table S3.1; Table 3 ). The models assuming normally distributed errors provided very poor fits, with strong positive bias for low levels of catches and negative bias for high levels of catches (Figs. S3.2 and S3.3). The parameters related to the number of individuals $\left(N_{0}\right.$ and $\left.R_{\mathrm{j}}\right)$ differed from the selected model by 2 or 3 orders of magnitude (cf. Tables S3.2 and S3.3 with Table 3). The parameters $\alpha$ and $\beta$ were particularly sensitive to the assumed error distribution, with low values for $\alpha$ and values near 0 for $\beta$.

The parameter estimates in Table 3 indicate a high value of natural mortality for this species, equivalent to $2.625 \mathrm{yr}^{-1}$. The number of individuals recruited to the fishery (perturbations $R_{j}$ ) varied by two orders of magnitude, from high recruitment in years 2012-2015 to very low recruitment in 2016 and 2017. In the last two years of the series recruitment levels were similar to those observed at the start of the series. The parameter $\alpha$ that links catches to effort was estimated to be greater than 1, suggesting that catches increase more than proportionally with increasing effort. Conversely, the estimate of $\beta$ was smaller than 1 suggesting hyperstability. These parameter values can be interpreted in the sense that relatively small increases of fishing effort (i.e., increase in the number of fishing days or the number of boats licensed to operate) would rapidly increase the rate of removals from the fishery $(\alpha>1)$, but the corresponding decrease in population numbers would be difficult to observe from catch per unit effort statistics due to hyperstability $(\beta<1)$.

The estimates of annual recruitment are plotted in Fig. 3A. Although the uncertainty in the parameter estimates is high, the figure shows that years 2013 and 2014 produced high recruitment compared with the following four years. Recruitment increased again in the last year of the series 2019. The harvest rates at the end of the season were high for the first three years of the series (final escapement between 42 and 51\%, Fig. 3B). In 2015 the very low recruitment compared to the previous two years translated into low catch rates at the start of the season (Fig. 1C), leading to a precautionary fishery closure and, consequently, very high escapement ( $83 \%$ at the end of the season). Note however that this high escapement did not result in high recruitment in 2016. Catch rates in 2016 were very low (Fig. 1C) but the co-management committee could not agree on fisheries closure, resulting in a very high proportion of removals and a very low escapement rates (36\% at the end of the season). In 2017 with low recruitment (Fig. 3A) and low catch rates (Fig. 1C) management action was taken to close the fishery at mid season and reopen it with very low effort towards the end of the season (Fig. 1B), which resulted in 
high escapement (75\%, Fig. 3B). In the last two years of the series with increasing recruitment (Fig. 3A), effort and catch rates have been kept high with relatively low escapement (30\% in 2018 and 44\% in 2019).

Fig. 3. A: Annual recruitment estimated by the Multi-Annual General Depletion model for the Mediterranean sandeel fishery with upper $95 \%$ confidence interval. B: Escapement rates (cumulative proportion of removals from fishing, Eq. (9)). The escapement at the end of the season is estimated (Eq. (8)) at $42 \%, 51 \%, 44 \%, 83$ $\%, 35 \%, 75 \%, 30 \%$ and $44 \%$ for the years $2012-2019$.

Comparing the biomass estimates of the MAGD model application with a surplus logistic model over the 2012-2019 period (Supplementary Material 2) shows that both models capture reasonably well the main dynamics of the Mediterranean sandeel population (Fig. 4). That is, high annual-averaged biomass in the first two years of the series used for the MAGD model application (2012-2013), low biomass in 2015-2017 and increasing biomass in the two recent-most years 2018-2019. Both models lead to very wide confidence intervals (Fig. 4). In the MAGD model the high uncertainty in biomass estimates is due primarily to the high values of the coefficient of variation of the estimates of initial number of individuals $\left(N_{0}\right)$ and recruitment size $\left(R_{\mathrm{j}}\right)$, that were as high as $200-500 \%$. The difficulty in estimating the number of individuals with precision may be attributed to the need to impose, in the model, a fixed natural mortality rate across years, which is unlikely to be realistic, when working at multi-annual scales. Roa-Ureta et al. (2015) and Lin et al. (2017) parameterized a generalized depletion model separately for individual years and showed that $M$ estimates can vary by a factor of 10 among years. On the other hand, it should be noted that high precision in the estimate of population numbers is less important than good estimates of catchability and effort stock parameters when advice is given in terms of harvest rates (Beddington et al., 1990). The results of the SPiCT model application showed that this model produced very high uncertainty around the parameters related to population growth dynamics, $r$, $K, m$ with confidence intervals around 2 to 10 times the estimate (Table S2.1). The model diagnostics based on residuals were unsatisfactory for the catch series (Fig. S2.2) and the retrospective analysis (figure not shown) provided widely diverging values, with estimates for fishing mortality varying by an order of 10 when applying the SPiCT model to data removing the most recent 1 to 4 years.

Fig. 4. Comparison of biomass estimated by the he Multi-Annual General Depletion (MAGD) model for the Mediterranean sandeel fishery and a surplus production model, estimated with Surplus Production in Continuous Time (SPiCT).

\section{Discussion}

The application of the MAGD model shows how it is possible to produce information of interest to fisheries managers (such as vulnerable biomass, fishing mortality, harvest rates or escapement rates) from data-limited stocks. Dowling et al. (2018) warn against the adoption of generic data-limited methods for stock assessment when data are limited. Nevertheless, here we take advantage of the existence of a good monitoring programme in the co-management plan for the sandeel boat seine fishery in Catalonia (Lleonart et al., 2014), which makes available accurate high frequency catch and effort data, complemented with basic biological data on growth and fish weight. Generalized depletion methods can be useful for the assessment of species that show short peaks of high abundance, which can be equated to pulses of recruitment at annual scale (for 
example in cephalopods, Roa-Ureta, 2012; Maynou, 2015), or other types of discrete incorporation of individuals to the fishery (for example, glass eels in Lin et al., 2017). The data requirements are relatively low, and data might be readily available for fisheries that are regularly monitored, but for which obtaining data such as catch-at-age or fishery-independent indices might prove impractical or too expensive.

The results of our "minimal stock assessment" (sensu Roa-Ureta, 2014) show that the exploitation of the Mediterranean sandeel (Gymnamodytes cicerelus) could continue to be carried out sustainably if fishing mortality is kept at very low levels (instantaneous exploitation rate $<0.04$ or annual harvest rates not exceeding $60 \%$ of the unfished population) because natural mortality is very high (estimated here at $M=2.6 \mathrm{yr}^{-1}$ ). The fluctuating population dynamics of the Mediterranean sandeel, whose year class strength depends exclusively on recruitment (Fig. 3A), imply periods of 2-3 years of high abundance (e.g. 2012-2014), followed by similar periods of very low abundance (2015-2017), when fishing mortality (or harvest rate) should be kept to a minimum. Retrospectively, the long fishery closure adopted during the second half of 2015 was probably an appropriate management measure, in a year when recruitment was much lower than the previous two years of the study (Fig. 3A). However, the fishery resumed in 2016 with high effort, which contributed to keep the stock at very low levels, forcing additional restrictions to fishing during the second half of 2017. The management measures envisaged in the co-management plan (from its inception), implementing an obligatory 2.5-month winter closure during spawning and closure of the fishery at any other time when perceived abundance is low, are good instruments to limit harvesting capacity. However, these measures are enforced not without difficulty because, in the absence of regular stock assessments, the perception of the fishing industry regarding stock size usually prevails over the more conservative approach of fisheries managers. In practice, and despite the high uncertainty in the parameter estimates (Table 3 ), the results of a MAGD model could be used in defining a robust and precautionary harvest strategy (Dowling et al., 2018) by applying eq. 9, above (taking into account estimation uncertainty and different scenarios of recruitment strength), so as to obtain an estimate of the escapement rate (or equivalently, cumulative harvest rate) at the end of each month, or another agreed time scale, and revise the catch quotas and / or the number of operating vessels to keep the exploitation level under some pre-specified value, for instance instantaneous exploitation rate $<0.04$ or annual escapement higher than $40 \%$. Supplementary material 4 provides an example at a weekly scale, for three different regimes of number of operating vessels per month: 10 vessels, 20 vessels, 30 vessels (note that the number of licenses is 26). If the management objective were to reach a proportional escapement of $40 \%$ (for example), the scenario with 10 active vessels per month would be safe and would guarantee escapement higher than $70 \%$ at the end of the season with $95 \%$ probability. A constant deployment of 20 vessels would help achieve $40 \%$ escapement on average at the end of the season, but with $5 \%$ probability of reaching this target around week 33. Finally, deploying 30 vessels would increase the likelihood of reaching $40 \%$ escapement already by mid-season, on average, and as early as week 15 (i.e. at the end of the second month) with 5\% probability. Naturally, the comanagement committee could take into account that sandeel sale prices are usually higher during the first half of the season, so as to distribute fishing effort unequally during the year to attempt to maximize fisheries rent, or other more elaborate schemes. A constant harvest rate strategy is likely to be over-conservative for years with very high recruitment for short-lived species fisheries and lead to reduced fishing opportunities. Note however that this is not necessarily negative for fisheries rent maximization, as very high landings may lead to a substantial decrease of ex-vessel sale 
price at short time scales. Among the growing body of data-limited methods (Downing et al., 2018), MAGD models are particularly suitable for geographically circumscribed stocks with short and annual peaks of recruitment, where the recruitment peak can be clearly associated to a perturbation in the model (Roa-Ureta, 2014; Lin et al., 2017), and not to other factors, such as immigration of fish from adjacent areas or range expansion of the fleet (but see Lin et al., 2017 for an extension of the model to accommodate immigration / emigration dynamics in Japanese glass eels). In this sense, the application to the Mediterranean sandeel fishery provides a good example because the stock is restricted to the shallow sandy bottoms of northeast Catalonia and not connected (at ecological scales) with other adjacent populations. The method has been successfully applied to other species that are less restricted in range, such as cuttlefish and striped red mullet in the NW Mediterranean (Maynou, 2015) or the Spanish mackerel in the Arabian Gulf (Roa-Ureta, 2014).

During the period analysed in this paper the spawning period and the values of the GSI (Gonado-Somatic Index) have remained essentially constant (Sanchez et al., 2016). Adults start spawning in November and the spawning period typically ends in March. Recruits start to be detected in the fishery as early as February some years and more typically in March. Due to the short period with data, it is not possible to establish a meaningful stock - recruitment relationship, but it is likely that a combination of density dependence and environmentally driven recruitment success play a significant role, as reported for the sandeel Ammodytes marinus in the North sea (Lindegren et al., 2018). These authors found that high abundance of 1-year sandeel had a negative effect on recruitment, probably because of intra-specific competition for food, while increased sea surface temperature was also detrimental to recruitment. In our case, we observed that during years of low population abundance, the mean size at the end of the season was larger than in years of high population abundance: in 2016 or 2017 (low stock size) mean size of the largest modal group was $12-13 \mathrm{~cm}$ TL, while in 2013 or 2018-2019 (high stock size) the size was comparatively lower, at less than $10.5 \mathrm{~cm}$ TL on average (Supplementary Material 5). We observed also that the number of individuals estimated by the model in December of each year was related to the recruitment strength in the month of peak recruitment in the following year $(\mathrm{r}=0.45)$, but the relationship was not statistically significant $(\mathrm{p}=0.32)$, likely due to the short data series. Martín et al. (2016) investigated the relationship between catches of spawners at the end of the season with catches of juveniles at the start of the following season and found a clear linear relationship, suggesting that annual recruitment strength is to some extent determined by parental biomass, as found in studies for a different sandeel species, A. marinus (Arnott and Ruxton, 2002; van Deurs et al., 2009).

Environmental factors can also affect the recruitment of sandeels. In A. marinus a negative relationship was detected between recruitment and the winter index of the North Atlantic Oscillation, which affects sea temperatures during the egg and larval period. Warmer sea temperatures correlated with poorer than average recruitment (Arnott and Ruxton, 2002). Similarly, Sánchez et al. (2019) reported a nonlinear relationship between December sea surface temperature and landings of G. cicerelus in the following year, suggesting that higher landings are obtained when winter temperature is low. The role of food availability on G. cicerelus recruitment success is unknown, but Arnott and Ruxton (2002) and van Deurs et al. (2009) detected a positive association between the recruitment of $A$. marinus and the abundance of the copepod prey, Calanus finmarchicus, at the time of hatching.

Circalittoral water mass dynamics is probably also highly relevant in addition to any density-dependent effect or winter temperature that may regulate recruitment strength in 
this species. For instance, recurrent strong winter storms, such as that caused by the depression "Gloria" in January 2020, can generate bottom speeds higher than $1 \mathrm{~m} \mathrm{~s}^{-1}$ at $20 \mathrm{~m}$ depth (J. Guillén, pers. comm.), which can cause resuspension of several tens of $\mathrm{cm}$ of the coarse sand top layer at $5 \mathrm{~m}$ depth, and about $10 \mathrm{~cm}$ at $20 \mathrm{~m}$ depth. It is not known how sandeels, as a burrowing animal, cope with strong habitat disturbance, but probably they move temporarily to deeper bottoms. The resuspension of sediments, with corresponding important sea floor disturbance, by storms in the Mediterranean inner continental shelf has been described several times in the Ebro Delta (Guillén et al., 2002, 2008).

An important result of our model application to management of this fishery is the non-linear response of catches with stock abundance or fishing effort. The abundance response coefficient $(\alpha)$ was much higher than 1 (estimated at 1.74), showing the disproportionately large effects of small increases in fishing effort (combination of number of days per month $\mathrm{x}$ number of vessels). High $\alpha$ is likely related to the technology used in the operation of this fishery, similar to a purse seine pelagic fishery: sand eel shoals are detected by electronic means and quickly rounded and hauled up with the boat seine, which makes the fishing operation highly efficient. On the other hand, the estimated effort response $(\beta)$ was lower than 1 (0.74), suggesting hyperstability of landings per unit effort, i.e. catches can be maintained at high levels despite shrinking stock (Harley et al., 2001). That is, relatively small increases of fishing effort (i.e. fishing days or high increase of catches) would rapidly increase the rate of removals from the fishery $(\alpha>1)$ but the corresponding decrease in population numbers would be difficult to detect from catch per unit effort statistics due to hyperstability $(\beta<1)$. Note that these two parameters were among the parameter estimates with lowest coefficient of variation (Table 3), which suggests that despite the high uncertainty inherent to assessments with data-limited methods fisheries managers should continue to tightly control fishing effort.

\section{Acknowledgements:}

The Fisheries Service of the Autonomous Government of Catalonia provided funding for this study. We thank also the fishers in the sonso fishery who collaborate in the monitoring of the fishery by facilitating data and samples. We appreciate the critical opinion of two independent reviewers and the Editor, which helped significantly improve the manuscript. 


\section{References}

Arnott, S.A., Ruxton, G.D., 2002. Sand eel recruitment in the North Sea: demographic, climatic and trophic effects. Mar. Ecol. Progr. Ser. 238, 199-210.

Beddington, J.R., Rosenberg, A.A., Crombie, J.A., Kirkwood, G.P., 1990. Stock assessment and the provision of management advice for the short fin squid fishery in Falkland Islands waters. Fish. Res. 8, 351-365.

Caddy, J. F., 2009. Practical issues in choosing a framework for resource assessment and management of Mediterranean and Black Sea fisheries. Med. Mar. Sci. 10, 83119.

Chapman D.G., 1974. Estimation of population size and sustainable yield of sei whales in the Antarctic. Rep. Int. Whal. Comm. 24, 82-90.

Colloca, F., Cardinale, M., Maynou, F., Giannoulaki, M., Scarcella, G., Jenko, K., Bellido, J. M., Fiorentino, F., 2013. Rebuilding Mediterranean fisheries: a new paradigm for ecological sustainability. Fish Fish. 14, 89-109.

Dowling, N.A., Smith, A.D.M., Smith, D.C., Parma, A.M., Dichmont, C.M., Sainsbury, K., Wilson, J.R., Dougherty, D.T., Cope, J.M., 2018. Generic solutions for datalimited fishery assessments are not so simple. Fish Fish. 20, 174-188. DOI: $10.1111 /$ faf.12329.

FAO, 2005. FAO-ICLARM Fish Stock Assessment Tools, v. 1.2.2. United Nations Food and Agriculture Organization, Rome. http://www.fao.org/fishery/topic/16072/en\#4

Guillén, J., Jiménez, J.A., Palanques, A., Gracia, V., Puig, P., Sánchez-Arcilla, A., 2002. Sediment resuspension across a fetch-limited tideless inner shelf. Cont. Shelf Res. 22(2), 305-325.

Guillén, J., Soriano, S., Demestre, M., Falqués, A., Palanques, A., Puig, P., 2008. Alteration of bottom roughness by benthic organisms in a sandy coastal environment. Cont. Shelf Res. 28, 2382-2392.

Haddon, M., 2011. Modelling and Quantitative Methods in Fisheries, 2nd Edition. CRC Press: Boca Raton, FL.

Harley, S. J., Myers, R. A., Dunn, A., 2001. Is catch-per-unit-effort proportional to abundance? Can. J. Fish. Aquat. Sci. 58, 1760-1772.

Hillborn, R., Walters, C. J., 1992. Quantitative Fisheries Stock Assessment. Chapman \& Hall, London.

Hoening, J.M., 2005. Empirical use of longevity data to estimate mortality rates. SEDAR33-RD17. SEDAR, North Charleston, SC. 8 pp.

Johannes, R. E., 1998. The case for data-less marine resource management: examples from tropical nearshore finfisheries. Trends Ecol. Evol. 13(6), 243-246.

Leydold, J., Hörmann, W., 2012. Runuran: R interface to the UNU.RAN random variate generators. In: $\mathrm{R}$ Package Version 0.20.0, http://CRAN.Rproject.org/package $=$ Runuran

Lin, Y.-J., Tzeng, W.-N., Han, Y.-S., Roa-Ureta, R.H., 2017. A stock assessment model for transit stock fisheries with explicit immigration and emigration dynamics: Application to upstream waves of glass eels. Fish. Res. 195, 130-140.

Lindegren, M., van Deurs, M., MacKenzie, B.R., Clausen, L.W., Christensen, A., Rindorf, A., 2018. Productivity and recovery of forage fish under climate change and fishing: North Sea sandeel as a case study. Fish. Oceanogr. 27(3), 212-221. 
Lleonart, J., Demestre, M., Martín, P., Rodón, J., Sainz-Trápaga, S., Sánchez, P., Segarra, I., Tudela, S., 2014. The co-management of the sand eel fishery of Catalonia (NW Mediterranean): the story of a process. Sci. Mar. 78, 87-93.

Lleonart, J., Maynou, F., 2003. Fish stock assessment in the Mediterranean: state of the art. Sci. Mar. 67(Suppl. 1), 37-49.

Martín, P., Colmenero, A., Demestre, M., García de Vinuesa, A., Lleonart, J., Recasens, L., Sánchez, P., 2016. Landings trend and SSB-R relationship in the NW Mediterranean boat seine sand eel fishery. Rapp. Comm. int. Mer Médit. 41.

Maynou, F., 2015. Application of a multi-annual generalized depletion model to the assessment of a data-limited coastal fishery in the western Mediterranean. Sci. Mar. 79(2), 157-168.

Pauly, D., 1980. On the interrelationships between natural mortality, growth parameters and mean environmental temperature in 175 fish stocks. J. Cons. CIEM 39(3), 175192.

Pedersen, M.W., Berg, C.W., 2017. A stochastic surplus production model in continuous time. Fish Fish. 18 (2), 226-43. https://doi.org/10.1111/faf.12174.

Prince, J., 2003. The barefoot ecologist goes fishing. Fish Fish. 4, 359-370.

Rikhter, V. A., Efanov, V. N., 1976. On one of the approaches to estimation of natural mortality of fish populations. ICNAF Research Document, 79/VI/8, 1-12.

Roa-Ureta, R.H., 2012. Modeling in-season pulses of recruitment and hyperstabilityhyperdepletion in the Loligo gahi fishery around the Falkland Islands with generalized depletion models. ICES J. Mar. Sci. 69, 1403-1415.

Roa-Ureta, R.H., 2014. Stock assessment of the Spanish mackerel (Scomberomorus commerson) in Saudi waters of the Arabian Gulf with generalized depletion models under data-limited conditions. Fish. Res. 171, 68-77. http://dx.doi.org/10.1016/i.fishres.2014.08.014

Sabatés, A., Demestre, M., Sánchez, P., 1990. Revision of the familiy Ammodytidae (Perciformes) in the Mediterranean with the first record of Gymnammodytes semisquamatus. J. Mar. Biol. Ass. U.K. 70, 493-504.

Sánchez, P., Colmenero, A. I., Demestre, M., García de Vinuesa, A., Lleonart, J., Martín, P., Recasens, L., 2016. Spawning season of Gymnammodytes cicerelus and G. semisquamatus in the NW Mediterranean. Rapp. Comm. int. Mer Médit. 41: 551.

Sanchez, P., Demestre, M., Recasens, L., Colmenero, A.I., Martín, P., 2019. Temperature during spawning affects sandeel landings in the Catalan coast (Western Mediterranean). Rapp. Comm. int. Mer Médit. 42: 281.

van Deurs, M., van Hal, R., Tomczak, M. T., Jonasdottir, S. H., Dolmer, P., 2009. Recruitment of lesser sandeel Ammodytes marinus in relation to density dependence and zooplankton composition. Mar. Ecol. Progr. Ser. 381, 249-258. 